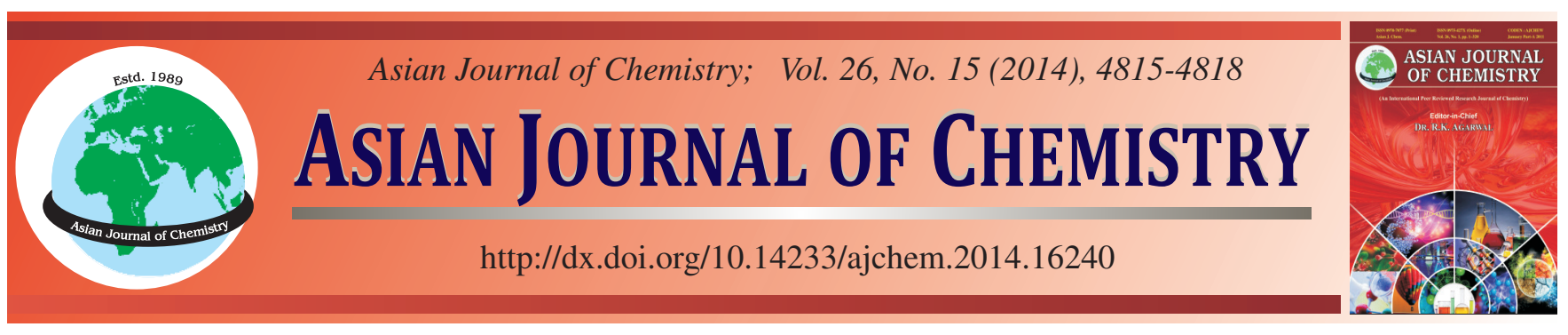

\title{
Effect of Microwave Irradiation on Synthesis of Phenol from Benzene Over Activated Carbon as Supported Catalysts
}

\author{
T. LIU ${ }^{1, *}$ and J.H. Hou ${ }^{2}$
}

${ }^{1}$ School of Chemistry \& Chemical Engineering, Xuzhou Institute of Technology, Xuzhou 221111, Jiangsu Province, P.R. China ${ }^{2}$ School of Food (Biology) Engineering, Xuzhou Institute of Technology, Xuzhou 221111, Jiangsu Province, P.R. China

*Corresponding author: E-mail: liutongcumt@126.com

Hydroxylation of benzene to phenol with hydrogen peroxide over catalysts prepared by $\mathrm{Fe}(\mathrm{III}), \mathrm{Cu}(\mathrm{II}), \mathrm{Co}$ (II) impregnated on activated carbon was examined at room temperature under microwave irradiation. The Fe(III)/activated carbon catalyst gave the highest conversion and yield. The effects of various reaction parameters, such as the different solvents, the amount of solvent, the amount of catalyst, the amount of hydrogen peroxide and the reaction time on the yield of phenol, were studied to obtain the optimal reaction conditions for phenol formation under microwave irradiation. A benzene conversion of $28.9 \%$ with a selectivity of $100 \%$ was obtained when the $5 \%$ loading amount of $\mathrm{Fe}(\mathrm{III})$ under optimized conditions.

Keywords: Hydroxylation, Benzene, Phenol, Hydrogen peroxide, Fe(III)/activated carbon.

\section{INTRODUCTION}

Phenol is an important intermediates for synthsis of various petrochemical and agrochemical products ${ }^{1,2}$. Nowadays approximately $95 \%$ of phenol produced by Cumme process consisting of three main reaction steps. However, this process suffers mainly from low atom utilization, low phenol yield, high energy consumption and the production of equal amount of acetone as the by product ${ }^{3,4}$. Therefore, development of alternative process for phenol production is of great importance ${ }^{5-8}$.

Carbon materials have been found useful in heterogeneous catalysis. The performance of carbon materials depends on their texture and surface chemistry. The surface area and porosity describe the texture of these materials. Larger surface area and higher porosity helps in higher dispersion of active phases. The surface chemistry of carbon materials can be ascribed to the surface oxygen containing chemical groups, which can be acidic, basic or neutral. The interactions between the surface groups and the active phase could also have a synergetic effect on the catalytic activity of these materials 9 .

Iron-containing catalysts, especially Fenton's reagents, were also extensively used for hydroxylation of benzene to phenol with $\mathrm{H}_{2} \mathrm{O}_{2}{ }^{10-12}$. Mechanistic studies suggested that both ferrous and ferric ions were necessary to maintain the radical reaction and that the reaction must be conducted in an acidic aqueous solution $^{13}$.
Compared to conventional heating, microwave irradiation heating has the following advantages for organic reactions, such as reducing heat transfer problems, energy efficiency, easy automation and incident power control ${ }^{14,15}$. Therefore, many reactions that do not occur by conventional heating can proceed under microwave irradiation, especially in a polar system $^{16}$.

In the present work, the hydroxylation of benzene to phenol was investigated over transition metals/activated carbon catalyst under microwave irradiation at room temperature. We have studied the effect of various parameters on the yield of phenol. An obvious promotion effect of the catalyst on the phenol yield and selectivity was observed for this reaction.

\section{EXPERIMENTAL}

Preparation of catalyst: Commercially available activated carbon materials were used as support for preparing catalysts containing different transition metals for the hydroxylation of benzene to phenol. Activated carbon was refluxed with $5 \mathrm{M}$ nitric acid for $3 \mathrm{~h}$ and the material was washed until neutral $\mathrm{pH}$ was attained. Then the solution was filtrated and the solid obtained was further dried at $70^{\circ} \mathrm{C}$ overnight in vacuum. Catalyst different transition metals/activated carbon were prepared according to the method reported by Tagawa.

Liquid-phase hydroxylation of benzene: A typical oxidation reaction is as follows: $1 \mathrm{~mL}$ of benzene, $30{ }^{\circ} \mathrm{C}$, described amounts of solvent, catalyst and $\mathrm{H}_{2} \mathrm{O}_{2}$ were added into a $50 \mathrm{~mL}$ 
CEM discover microwave reactor with a magnetical stirrer. The reactor was kept for 5-25 $\mathrm{min}$. Then the reactor was immediately cooled to room temperature by purging compressed air. The reaction mixtures were analyzed by GC/MS. The conversion of each substrate was calculated as molar ratio of the substrate remained in the reaction mixture to that added and the selectivity of each product was calculated as molar ratio of the product to all the products.

Characterization: X-ray diffraction (XRD) measurements were carried out with a D/max-RA X-ray diffractometer (Rigaku, Japan), $\mathrm{CuK}_{\alpha}$ radiation at a scan rate of $3 \% \mathrm{~min}$. The tube voltage and current were $35 \mathrm{kV}$ and $35 \mathrm{~mA}$, respectively. The phases were identified by comparing the diffraction patterns to standard powder XRD cards compiled by the Joint Committee on Powder Diffraction Standards (JCPDS).

The BET surface area, total pore volume and pore size distribution of the fresh catalysts were determined via $\mathrm{N}_{2}$ physisorption at the normal boiling point of $\mathrm{N}_{2}\left(-196^{\circ} \mathrm{C}\right)$, using an autosorb-1MP instrument (Quanta chrome, USA).

The terms of reaction performance were defined as follows:

$$
\begin{gathered}
\text { Yield of phenol }=\frac{\text { mole of phenol produced }}{\text { Initial mole of benzene }} \\
\text { Selectivity of phenol }=\frac{\text { mole of phenol produced }}{\text { mole of benzene reacted }}
\end{gathered}
$$

\section{RESULTS AND DISCUSSION}

The transition metal/activated carbon catalysts were prepared by impregnated method from three precursors: iron(III) trichloride, copper(II) nitrate, cobalt(II) nitrate. The effects of the three transition metal species on the benzene conversion, phenol selectivity and yields for different catalysts are summarized in Table-1. It was noted that the activity of transition metal catalysts followed the order: $\mathrm{Fe}(\mathrm{III})>\mathrm{Cu}(\mathrm{II})>\mathrm{Co}$ (II). However, BET surface area and pore volume followed the opposite order (as shown in Table-2). The results indicate that

\begin{tabular}{|c|c|c|c|}
\hline \multicolumn{4}{|c|}{$\begin{array}{l}\text { EFFECT OF DIFFERENT TRANSITION METAL SPECIES/ } \\
\text { ACTIVATED CARBON CATALYSTS PREPARED BY } \\
\text { IMPREGNATED METHOD ON THE YIELD OF PHENOL }\end{array}$} \\
\hline Catalyst & \multicolumn{2}{|c|}{ Conversion (\%) } & electivity (\%) \\
\hline $\mathrm{FeCl}_{3}$ & \multicolumn{2}{|c|}{28.2} & 100 \\
\hline $\mathrm{Cu}\left(\mathrm{NO}_{3}\right)_{2}$ & \multicolumn{2}{|c|}{7.5} & 97 \\
\hline $\mathrm{Co}\left(\mathrm{NO}_{3}\right)_{2}$ & \multicolumn{2}{|c|}{3.1} & 90 \\
\hline \multicolumn{4}{|c|}{$\begin{array}{l}\text { Reaction conditions: } 0.4 \mathrm{~g} \text { catalyst, } 1 \mathrm{~mL} \text { benzene, } 3 \mathrm{~mL} \mathrm{H}_{2} \mathrm{O}_{2}, 15 \mathrm{~mL} \\
\text { acetonitrile, } 35^{\circ} \mathrm{C}, 20 \mathrm{~min}\end{array}$} \\
\hline \multicolumn{4}{|c|}{$\begin{array}{c}\text { TABLE } 2 \\
\text { BET DATA FOR DIFFERENT TRANSITION METAL } \\
\text { SPECIES/ACTIVATED CARBON CATALYSTS } \\
\text { PREPARED BY IMPREGNATED METHOD }\end{array}$} \\
\hline $\begin{array}{l}\text { Catalyst } \\
(5 \mathrm{wt} \%)\end{array}$ & $\begin{array}{l}\text { Surface area } \\
\quad\left(\mathrm{m}^{2} \mathrm{~g}^{-1}\right)\end{array}$ & $\begin{array}{c}\text { Total pore } \\
\text { volume }\left(\mathrm{mL} \mathrm{g}^{-1}\right)\end{array}$ & $\begin{array}{l}\text { Average pore } \\
\text { diameter }(\mathrm{nm})\end{array}$ \\
\hline $\mathrm{FeCl}_{3} / \mathrm{C}$ & 1107 & 1.04 & 3.76 \\
\hline $\mathrm{Cu}\left(\mathrm{NO}_{3}\right)_{2} / \mathrm{C}$ & 1280 & 1.24 & 3.85 \\
\hline $\mathrm{Co}\left(\mathrm{NO}_{3}\right)_{2} / \mathrm{C}$ & 1290 & 1.27 & 3.90 \\
\hline
\end{tabular}
the Fe(III) was located more at the surface of activated carbon than other metal species. In addition, it is clear that the type of precursor influenced the metal distribution in the catalysts. As known, the catalytic activity of the transition metal species is dependent on the outer d electron density. Lesser the electron density, greater is the capacity of these transition metals to activate oxidant species like hydrogen peroxide. From the point of view of electron density the catalyst activity should be $\mathrm{Fe}(\mathrm{III})>\mathrm{Cu}(\mathrm{II})>\mathrm{Co}(\mathrm{II})$. $\mathrm{So}, \mathrm{Fe}(\mathrm{III})$ is considered as a suitable precursor.

Effect of the Fe(III) loading: The XRD patterns of samples with various percentages of $\mathrm{Fe}(\mathrm{III})$ /activated carbon catalysts prepared by impregnated method are shown in Fig. 1. No obvious peaks of $\mathrm{Fe}_{2} \mathrm{O}_{3}$ crystalline phases were found in the XRD patterns, suggesting that no bulk metal oxide was presented in all catalysts, which could be due to the low metal loading or to the oxide being in the amorphous state. The influence of the Fe(III) loading (e.g., 3, 5, 7\%) on the benzene conversion and phenol selectivity are summarized in Table- 3 . It is found that the conversion increased with increasing $\mathrm{Fe}(\mathrm{III})$ loading, while the selectivity decreased, thus an optimum yield of $5 \%$ was observed. The increases in conversion may be due to the increased amount of metal active species, however, the excessive metal species promoted the produce of the byproducts, decreased the selectivity of phenol.

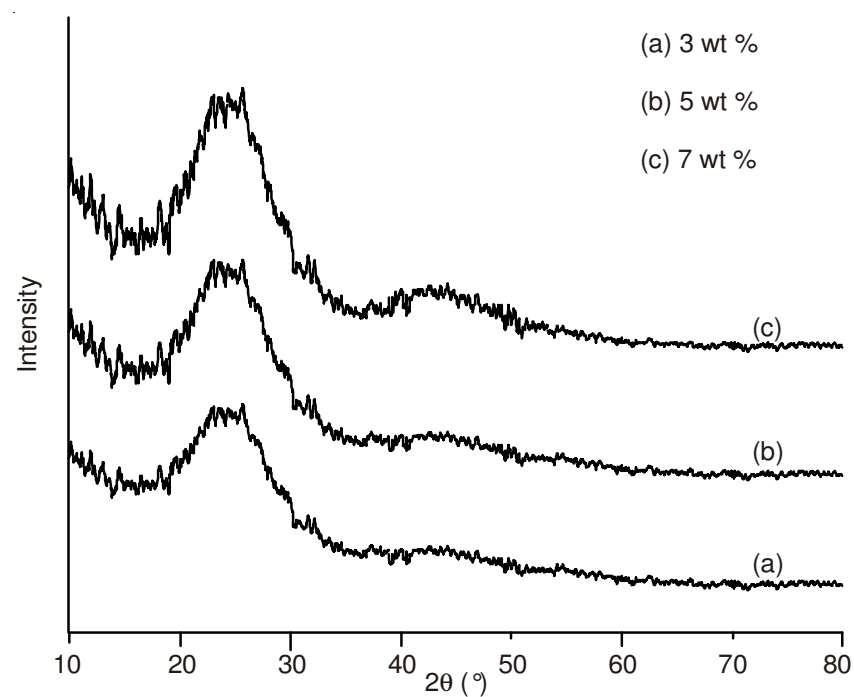

Fig. 1. XRD patterns of different loading contents in $\mathrm{FeCl}_{3}$ /activated carbon catalysts prepared by impregnated method]

The specific surface area of the catalysts decreased with increased amount of metal loading (Table-4), indicating that some micropore blockage by metal deposition on pore mouth.

\begin{tabular}{|c|c|c|}
\hline \multicolumn{3}{|c|}{ 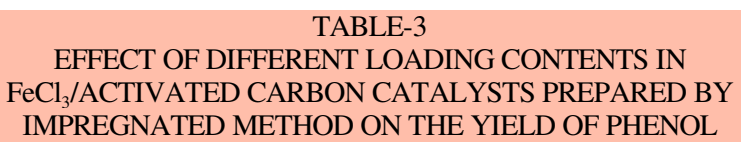 } \\
\hline $\mathrm{FeCl}_{3} / \mathrm{C}(\mathrm{wt} \%)$ & Conversion $(\%)$ & Selectivity (\%) \\
\hline 3 & 23.5 & 100 \\
\hline 5 & 28.2 & 100 \\
\hline 7 & 30.5 & 87 \\
\hline
\end{tabular}
Thus, $5 \%$ was selected as an optimum Fe(III) loading.

Reaction conditions: $0.4 \mathrm{~g}$ catalyst, $1 \mathrm{~mL}$ benzene, $3 \mathrm{~mL} \mathrm{H}_{2} \mathrm{O}_{2}, 15 \mathrm{~mL}$ acetonitrile, $35^{\circ} \mathrm{C}, 20 \mathrm{~min}$ 


\begin{tabular}{cccc}
\hline \multicolumn{4}{c}{ TABLE-4 } \\
BET DATA FOR DIFFERENT LOADING CONTENTS IN \\
FECL 3 /ACTIVATED CARBON CATALYSTS \\
PREPARED BY IMPREGNATED METHOD \\
\hline \multirow{2}{*}{$\mathrm{FeCl}_{3} / \mathrm{C}(\mathrm{wt} \%)$} & $\begin{array}{c}\text { Surface area } \\
\left(\mathrm{m}^{2} \mathrm{~g}^{-1}\right)\end{array}$ & $\begin{array}{c}\text { Total pore } \\
\text { volume }\left(\mathrm{mL} \mathrm{g}^{-1}\right)\end{array}$ & $\begin{array}{c}\text { Average pore } \\
\text { diameter }(\mathrm{nm})\end{array}$ \\
\hline 3 & 1185 & 1.06 & 3.80 \\
5 & 1170 & 1.04 & 3.76 \\
7 & 1160 & 1.03 & 3.74 \\
\hline
\end{tabular}

\section{Effect of reaction conditions on the yield of phenol under} microwave irradiation

Effect of type solvent: Benzene hydroxylation with hydrogen peroxide was performed in a triphasic system (e.g., organic, aqueous and catalyst). Solvent was used to reduce the reactants transfer resistance by helping dissolve $\mathrm{H}_{2} \mathrm{O}_{2}$ into the benzene phase. A volume of $15 \mathrm{~mL}$ of various solvents was added. The catalytic performance of the system with various solvents (e.g., acetonitrile, methanol, isopropyl alcohol, acetone and ethanol) over $\mathrm{Fe}(\mathrm{III})(5 \mathrm{wt} \%)$ /activated carbon catalysts under microwave irradiation are summarized in Fig. 2. It was found that acetonitrile as solvent gave obviously higher conversion compared to other solvent. This could be attributed to acetonitrile has a greater affinity to the catalytic surface than other solvents, which could lead to more effective transport of the reactants to the catalyst active $\operatorname{sites}^{10}$. So, we focus our attention on acetonitrile as the solvent.

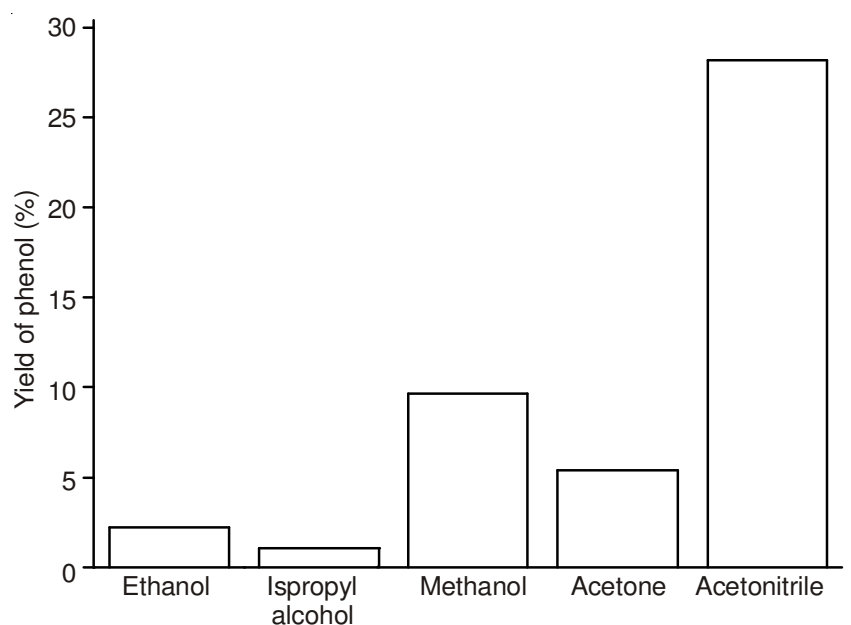

Fig. 2. Effect of solvents on the yield of phenol. Reaction conditions: $0.4 \mathrm{~g}$ catalyst, $1 \mathrm{~mL}$ benzene, $3 \mathrm{~mL} \mathrm{H} \mathrm{H}_{2} \mathrm{O}_{2}, 15 \mathrm{~mL}$ solvent, $35^{\circ} \mathrm{C}$, $20 \mathrm{~min}$

Compared to conventional heating mothed, as high dipole and the high dielectric constant of the aprotic solvent, acetonitrile will allow reaction system to reach a predetermined temperature in a short period of time with the microwave absorption of electromagnetic energy. The reactant of benzene and $\mathrm{H}_{2} \mathrm{O}_{2}$ was accelerated to dissolve in acetonitrile and then make a good contact with them will help to accelerate the reaction process, reduce the temperature gradient reason.

Effect of solvent amount: The catalytic performance of the reaction system using different volumn of acetonitrile over $\mathrm{Fe}(\mathrm{III})(5 \mathrm{wt} \%) /$ activated carbon catalysts under microwave irradiation showed in Fig. 3. Phenol yield significantly increased with increasing acetonitrile amount up to $15 \mathrm{~mL}$, but

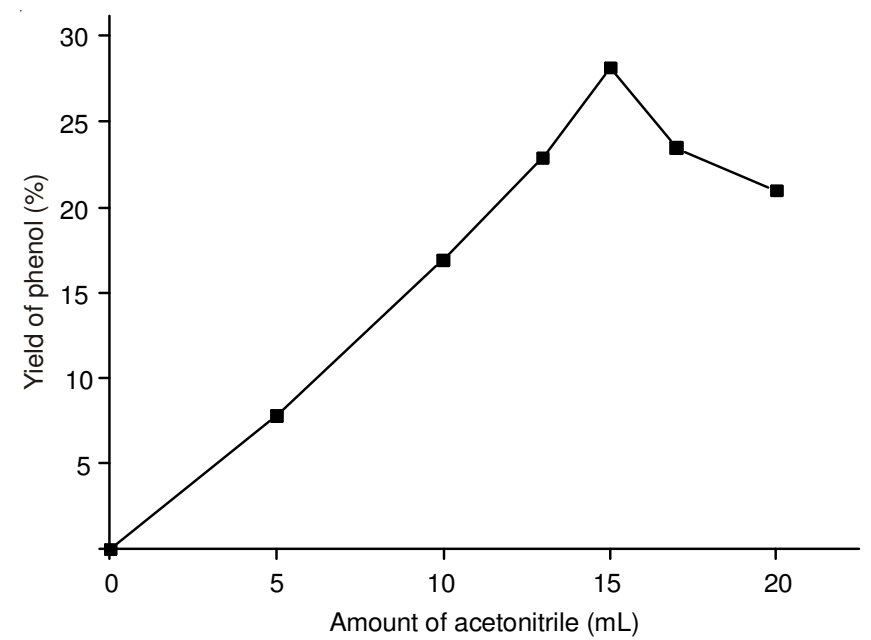

Fig. 3. Effect of acetonitrile amount on the yield of phenol. Reaction conditions: $0.4 \mathrm{~g}$ catalyst, $1 \mathrm{~mL}$ benzene, $3 \mathrm{~mL} \mathrm{H}_{2} \mathrm{O}_{2}, 35^{\circ} \mathrm{C}, 20 \mathrm{~min}$

then decreased with further increase in acetonitrile amount. Solvent can be dissolved both in benzene and in $\mathrm{H}_{2} \mathrm{O}_{2}$ aqueous solution, adding proper amount of acetonitrile improves interaction between benzene and ${ }^{\circ} \mathrm{OH}$ formed from $\mathrm{H}_{2} \mathrm{O}_{2}$ and thereby increases phenol yield, but superfluous addition of acetonitrile decreases the concentrations of both benzene and $\mathrm{H}_{2} \mathrm{O}_{2}$ and subsequently decreases phenol yield instead. Therefore, $15 \mathrm{~mL}$ was selected as an optimum solvent amount.

Effect of amount of $\mathrm{H}_{2} \mathrm{O}_{2}$ : The influence of $\mathrm{H}_{2} \mathrm{O}_{2}$ as the oxidant reagent on the yield of phenol was investigated using $\mathrm{Fe} /$ activated carbon as the catalyst and the effect of the amount of $\mathrm{H}_{2} \mathrm{O}_{2}$ on the yield of phenol using $\mathrm{Fe}$ (III) (5 wt \%)/activated carbon catalysts under microwave irradiation is illustrated in Fig. 4. No phenol was obtained without the use of $\mathrm{H}_{2} \mathrm{O}_{2}$. The phenol yield was found to increase with the increase of the amount of $\mathrm{H}_{2} \mathrm{O}_{2}$ and reached a maximum value of $28.2 \%$ at $3 \mathrm{~mL}$. Further increase of the amount of $\mathrm{H}_{2} \mathrm{O}_{2}$ had a reverse influence on the phenol yield, which result from the further oxidation of the phenol formed, the benzoquinone was observed $^{3}$. Therefore, $3 \mathrm{~mL}$ is considered as a suitable amount in this reaction.

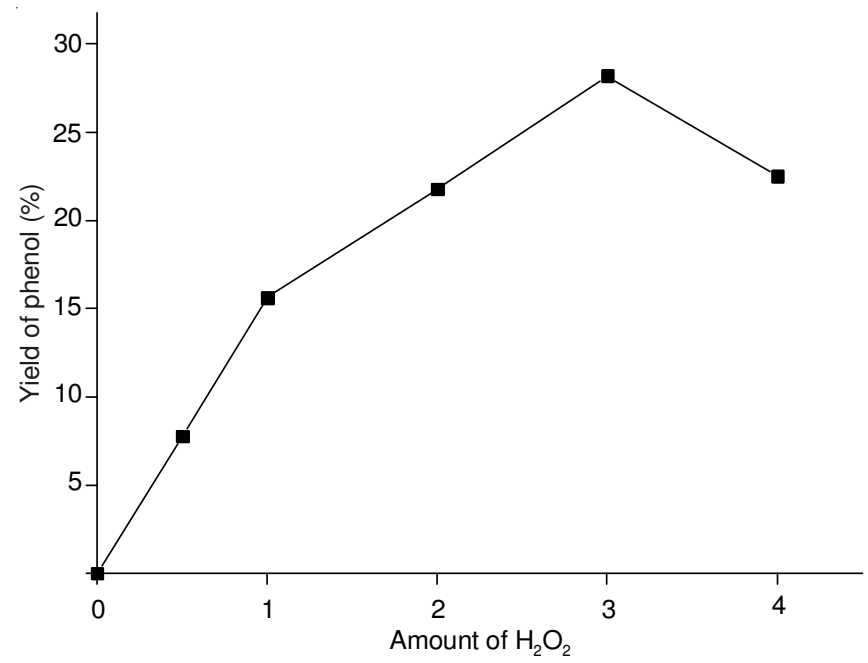

Fig. 4. Effect of $\mathrm{H}_{2} \mathrm{O}_{2}$ amount on the yield of phenol. Reaction conditions: $0.4 \mathrm{~g}$ catalyst, $1 \mathrm{~mL}$ benzene, $15 \mathrm{~mL}$ acetonitrile, $35^{\circ} \mathrm{C}, 20 \mathrm{~min}$ 
Effect of the amount of catalyst: The result for the effect of the amount of $\mathrm{Fe}$ (III)/activated carbon catalyst on the yield of phenol over Fe(III) (5 wt \%)/activated carbon catalysts under microwave irradiation is shown in Fig. 5. It is obvious that no phenol was detected without the use of $\mathrm{Fe}$ (III)/activated carbon catalyst, indicating that the presence of $\mathrm{Fe}$ (III) essential for performing the reducer. The yield of phenol increased greatly from 13.5 to $28.2 \%$ when the amount of catalyst increased from $0.2 \mathrm{~g}$ to $0.4 \mathrm{~g}$. On the other hand, a further increase in the amount of catalyst to $0.5 \mathrm{~g}$ caused a decrease in the yield of phenol. This may be due to the increase of catalyst amount, will cause the increase of the hydroxyl free radical generation, to improve the yield of phenol; but an excess of hydroxyl free radical generated inevitably promoted phenol side effects occured, reduced the yield of phenol. Therefore, $0.4 \mathrm{~g}$ is chosen as a suitable amount in this reaction.

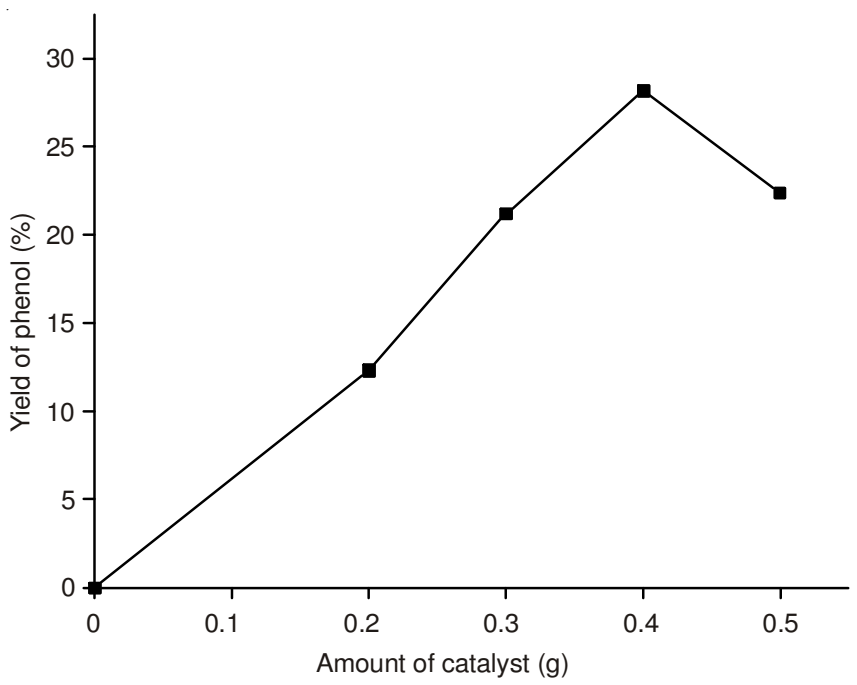

Fig. 5. Effect of catalyst amount on the yield of phenol. Reaction conditions: $1 \mathrm{~mL}$ benzene, $3 \mathrm{~mL} \mathrm{H} \mathrm{O}_{2}, 15 \mathrm{~mL}$ acetonitrile, $35^{\circ} \mathrm{C}$, $20 \min$

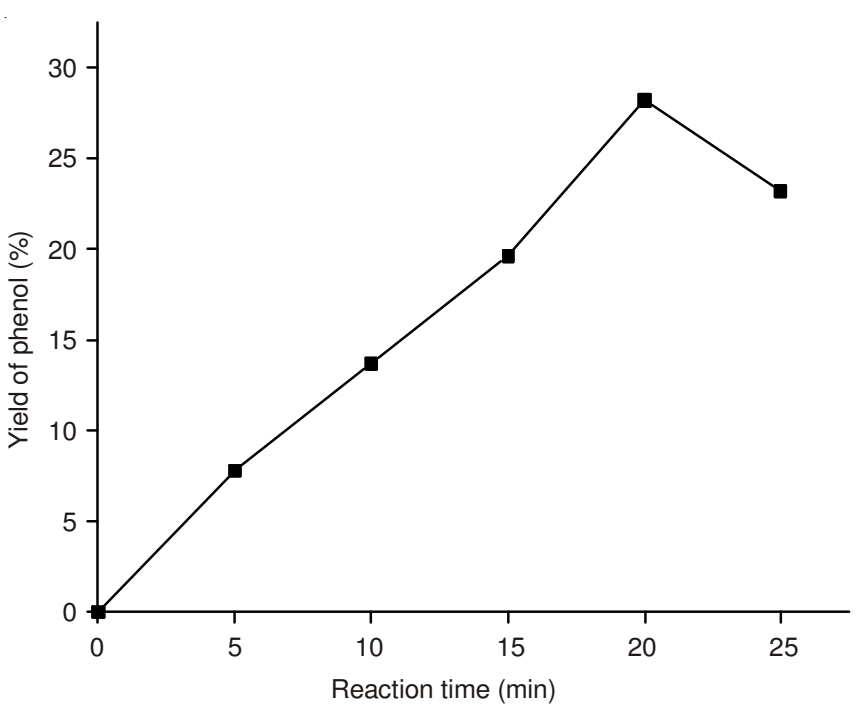

Fig. 6. Effect of reaction time on the yield of phenol. Reaction conditions: $0.4 \mathrm{~g}$ catalyst, $1 \mathrm{~mL}$ benzene, $3 \mathrm{~mL} \mathrm{H}_{2} \mathrm{O}_{2}, 15 \mathrm{~mL}$ acetonitrile, $35^{\circ} \mathrm{C}$
Effect of reaction time: The influence of reaction time on the yield of phenol over Fe/activated carbon catalyst using $\mathrm{Fe}(\mathrm{III})(5 \mathrm{wt} \%) /$ activated carbon catalysts under microwave irradiation is illustrated in Fig. 6. When the reaction time increased from $5 \mathrm{~min}$ to $20 \mathrm{~min}$, the yield increased sharply from 15.1 to $28.2 \%$. However, further increase of reaction time has a reverse influence on the phenol yield. So, $20 \mathrm{~min}$ is considered as a suitable reaction time in this reaction.

Conventional heating method often cause oxidation reaction only in active site, which is due to uneven heating. Microwave irradiation can make reaction system in a short period of time to an indicated temperature, in turn, increase the reactant and contact probability, thus increasing the activity of the reaction.

\section{Conclusion}

The hydroxylation of benzene to phenol with hydrogen peroxide was performed at room temperature using various transition metals, $\mathrm{Fe}(\mathrm{III}), \mathrm{Cu}$ (II) and $\mathrm{Co}(\mathrm{II})$ impregnated on activated carbon. The activity was ordered as follows: Fe(III) $>\mathrm{Cu}$ (II) $>\mathrm{Co}(\mathrm{II})$. Coupled conventionally heated method gives phenol yield of $19.6 \%$, activated carbon supported $\mathrm{Fe}$ (III) catalyst showed better catalytic performance for the direct hydroxylation of benzene to phenol by hydrogen peroxide under microwave irradiation, at the optimum reactions conditions: $1 \mathrm{~mL}$ benzene, $3 \mathrm{~mL} 30 \%$ aqueous solution of $\mathrm{H}_{2} \mathrm{O}_{2}, 0.4 \mathrm{~g}$ catalyst, $15 \mathrm{~mL} \mathrm{CH}_{3} \mathrm{CN}, 35^{\circ} \mathrm{C}$ reaction temperature and 20 min reaction time.

\section{ACKNOWLEDGEMENTS}

The authors are grateful to the Scientific Research Item of Xuzhou Institute of Technology (grant No. XKY2012304) for the financial support.

\section{REFERENCES}

1. H. Ehrich, H. Berndt, M.M. Pohl, K. Jähnisch and M. Baerns, Appl. Catal. A, 230, 271 (2002).

2. K. Lemke, H. Ehrich, U. Lohse, H. Berndt and K. Jähnisch, Appl. Catal. A., 243, 41 (2003).

3. G. Tanarungsun, W. Kiatkittipong, P. Praserthdam, H. Yamada, T. Tagawa and S. Assabumrungrat, Catal. Commun., 9, 1886 (2008).

4. J. Zhang, Y. Tang, G. Li and C.W. Hu, Appl. Catal. A, 278, 251 (2005).

5. M. Bahidsky and M. Hronec, Catal. Today, 99, 187 (2005).

6. M. Tani, T. Sakamoto, S. Mita, S. Sakaguchi and Y. Ishii, Angew. Chem. Int. Ed., 44, 2586 (2005).

7. X.K. Hu, L.F. Zhu, X.Q. Wang, B. Guo, J. Xu, G. Li and C. Hu, J. Mol. Catal. Chem., 342, 41 (2011).

8. A. Nemati Kharat, S. Moosavikia, B. Tamaddoni Jahromi and A. Badiei, J. Mol. Catal. Chem., 348, 14 (2011).

9. F. Rodríguez-Reinoso, Carbon, 36, 159 (1998).

10. J.-S. Choi, T.-H. Kim, K.-Y. Choo, J.-S. Sung, M.B. Saidutta, S.-D. Song and Y.-W. Rhee, J. Porous Mater., 12, 301 (2005).

11. S. Tamagaki, K. Hotta and W. Tagaki, Chem. Lett., 11, 651 (1982).

12. C. Walling, G.M. El-Taliawi and R.A. Johnson, J. Am. Chem. Soc., 96, 133 (1974).

13. C. Walling and R.A. Johnson, J. Am. Chem. Soc., 97, 363 (1975).

14. C. Bonnet, L. Estel, A. Ledoux, B. Mazari and A. Louis, Chem. Eng. Process., 43, 1435 (2004).

15. P.A. Enquist, P. Nilsson and M. Larhed, Org. Lett., 5, 4875 (2003).

16. P. Lidström, J. Tierney, B. Wathey and J. Westman, Tetrahedron, 57, 9225 (2001). 